\title{
Preliminary study on the microstructure and mechanical properties of dissimilar joints of aluminum alloy and pure copper by FSW
}

\author{
Daniela-Monica Iordache*, Cătălin-Marian Ducu, Eduard-Laurentiu Niţu, Doina Iacomi, \\ and Adriana-Gabriela Plăiaşu \\ University of Piteşti, Manufacturing and Industrial Management Department, Târgu din Vale Street \\ No.1, Piteşti, Romania
}

\begin{abstract}
Aluminum and copper are two common metals and $\mathrm{Al}-\mathrm{Cu}$ joints are commonly used in the power industry. Overlay joints of 3105 aluminum alloy and commercially pure copper were produced by FSW, microstructure and mechanical properties was investigated. A combination of optical and scanning electron microscopy is used to characterize the microstructures in the copper and heat affected zone in the aluminum near the fusion line. The hardness distribution was analyzed and residual stresses were measured at the stir zone, copper side and aluminum alloy side.
\end{abstract}

\section{Introduction}

Joining of metals and materials is an important stage in manufacturing and assembling of industrial and engineering parts. Friction stir welding is a variant of friction welding and represents the newest welding process introduced in practice [1-2]. This process was invented in Cambridge, at the Welding Institute in 1991. The procedure allows joining without melting the parts, without their relative pressing and without filling. Welds are the result of a complex heating action by friction and plastic deformation by means of a tool moving in rotation and translation. Friction stir welding is mainly used to weld aluminum and its alloys, resulting strong joints with good plasticity, although aluminum is difficult to weld by conventional methods [3]. Current research in the field are oriented towards welding dissimilar materials (welded plates have different materials) used especially in the construction of parts specific to the aerospace industry, transport, automotive industry, electric power industry [4-5]. Aluminum and copper are two common metals in the electric power industry, but the dissimilar combination of aluminum and copper is generally difficult for fusion welding because of the wide difference in their physical, chemical and mechanical properties [6-8].

Considering current research, joining $\mathrm{Al}-\mathrm{Cu}$ is of particular importance in future electric cars as electrodes for batteries or electrical conductor [7-9].

In the present work, the microstructure and mechanical properties of dissimilar friction stir welded overlay joints of aluminum alloy (EN AW 3105) and pure copper $(\mathrm{Cu})$ were evaluated.

${ }^{*}$ Corresponding author: monica.iordache@upit.ro 
Thus, the macrostructure and the microstructure of the joint were analyzed using electron microscopy and the HV micro-hardness was measured.

\section{Experimental procedure}

In the experimental part of this investigation, the welded samples are overlay joints between two plates, where the dimensions are $160 \times 80\left[\mathrm{~mm}^{\wedge} 2\right]$ and the thickness is $2[\mathrm{~mm}]$. The friction stir welds have been carried out on samples of $\mathrm{Cu} 99$ and EN-AW-3005 with the composition listed in Tables 1 and 2 .

Table 1. Chemical composition [\%] of material EN-AW-3005 (in weight percent).

\begin{tabular}{|c|c|c|c|c|c|c|c|c|c|c|}
\hline Alloy & $\mathbf{S i}$ & $\mathbf{F e}$ & $\mathbf{C u}$ & $\mathbf{M n}$ & $\mathbf{M g}$ & $\mathbf{C r}$ & $\mathbf{Z n}$ & $\mathbf{T i}$ & other & Al \\
\hline 3005 & 0.6 & 0.7 & 0.3 & $1-1.5$ & $0.2-0.6$ & 0.1 & 0.25 & 0.1 & 0.05 & Rest \\
\hline
\end{tabular}

Table 2. Chemical composition [\%] of material $\mathrm{Cu} 99$ (in weight percent).

\begin{tabular}{|c|c|c|c|c|c|c|}
\hline Alloy & $\mathrm{Ag}$ & $\mathrm{As}$ & $\mathrm{Bi}$ & $\mathrm{Cu}+\mathrm{Ag}$ & $\mathrm{Fe}$ & $\mathrm{Pb}$ \\
\hline $\mathrm{Cu} 99$ & 0.15 & 0.2 & 0.005 & 0.99 & 0.1 & 0.03 \\
\hline
\end{tabular}

Here, we used a cylindrical tool where the diameter of the shoulder is $20 \mathrm{~mm}$ and the pin is conical, Figure 1. The length of the pin was 2.7 [mm]. The values of the process parameters were the same in both cases: (i) the rotation speed of the pin 1200 [rpm] (rotation per minute), (ii) feed rate $70[\mathrm{~mm} / \mathrm{min}]$.

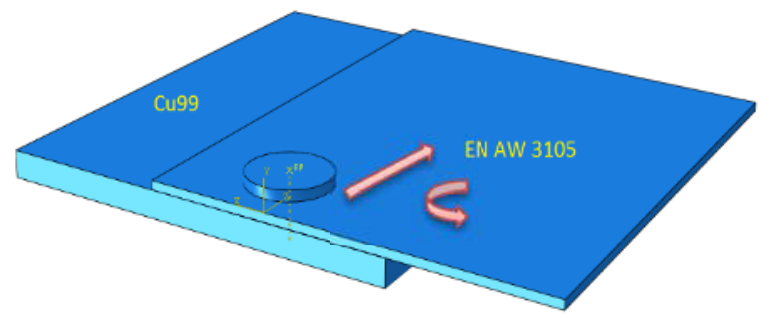

Fig. 1. Schematic illustration of dissimilar FSW.

Welded test specimens were cut perpendicular to the welding direction and prepared by standard methods for the analysis of microstructure. Microstructure analysis was performed by Transmission Electron Microscopy (TEM) using the 5000-SU Hitachi microscope coupled with an EDS spectrometer for the elemental analysis of the joined area.

The voltage was $25 \mathrm{kV}$ and the working distance varied between 9-15 $\mathrm{mm}$ in High Vacuum MODE. The hardness was measured using the Vickers method by the equipment Falcon 500 Innovatest. It has achieved a line of hardness with the step between two fingerprints of $1 \mathrm{~mm}$.

To determine the residual stress there was used the method with the Rigaku AutoMate II diffractometer, the tensions being determined on the crystallographic direction by normal perpendicular on the section of the test samples.

\section{Results and discussions}

\subsection{Macroscopic and microscopic analysis}

The macroscopic appearance of the welded joint was analyzed at different times / sequences of the welding process and it was noticed that the core has a time-varying evolution in terms 
of configuration of sizes and distribution of compounds characteristic of the two materials. For example:

- at $60 \mathrm{~mm}$ from the start of the welding process, the portion of the mixing zone (core) expands mainly from the aluminum alloy to copper (Figure 2),

- after $150 \mathrm{~mm}$ of welding, along with the increase of temperature developed during the process, it is observed that the mixing zone expands to a greater extent in the copper alloy (Figure 3).

The core portion of aluminum alloy consists of the following regions:

- an area of the core, lighter in color and located at the top in Al,

- an area under the previous one which contains many particles rich in $\mathrm{Cu}$ and expanding in the basic material $\mathrm{Cu}$ (see figure 3 ).

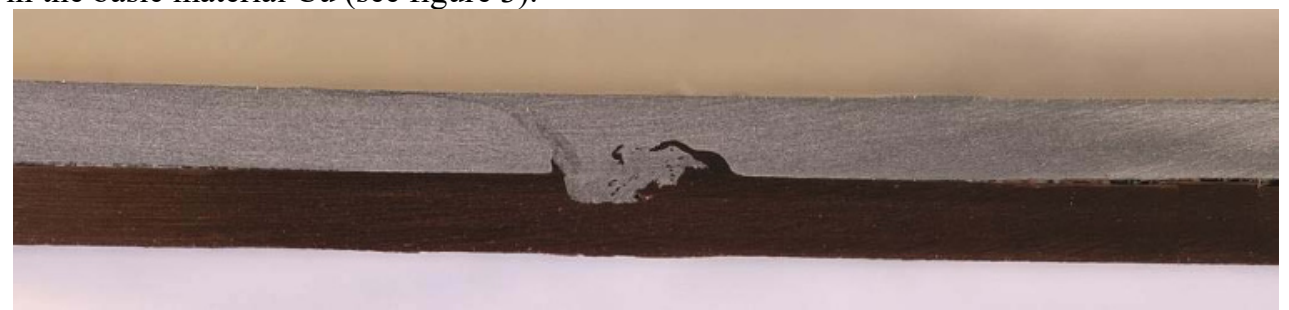

Fig. 2. Macroscopic appearance in samples taken at $60 \mathrm{~mm}$ from the start of the weld.

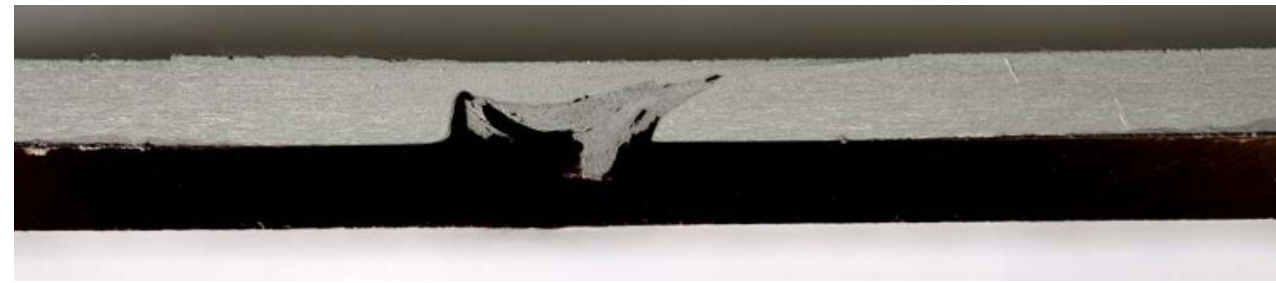

Fig. 3. Macroscopic appearance in samples taken at $150 \mathrm{~mm}$ from the start of the weld.

There were investigated three areas of joint, Figure 4, images of the weld nugget, acquired by EDS technique, are shown in Figure 5.

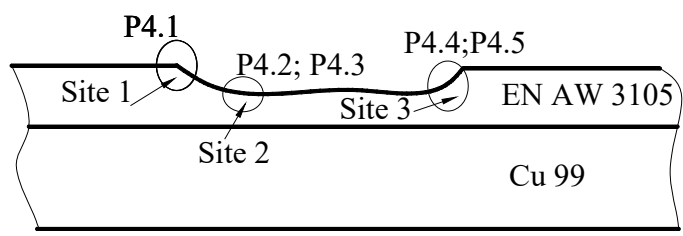

Fig. 4. Position of analyzed areas.

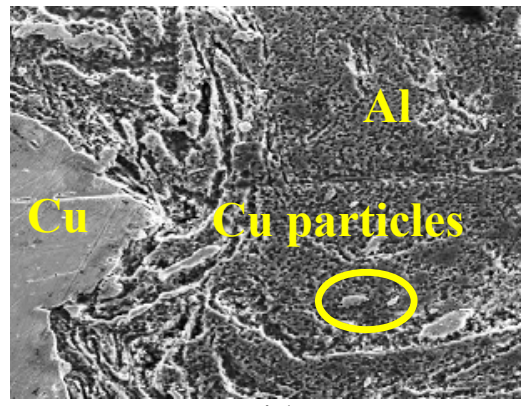

P4.1 


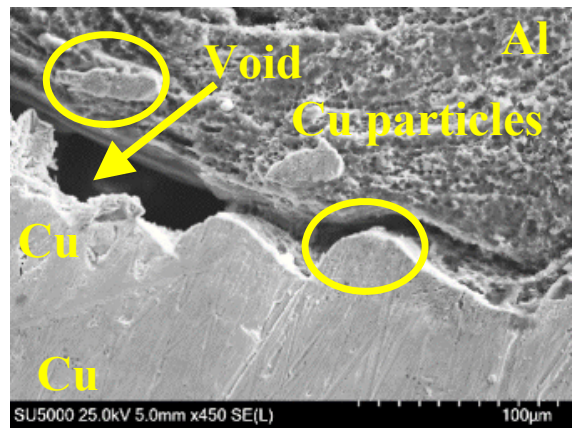

P4.2

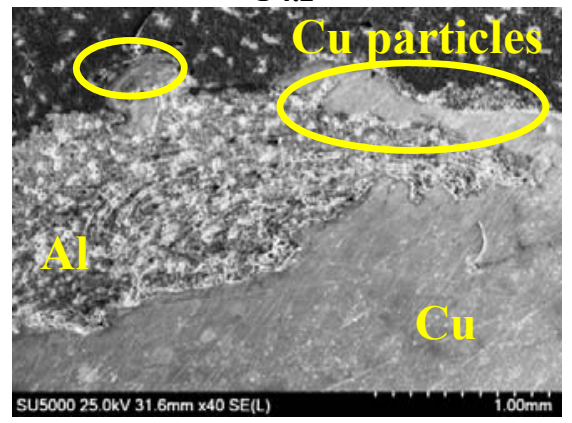

P4.4

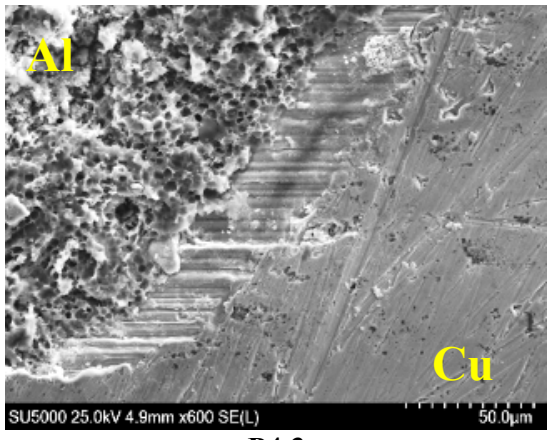

P4.3

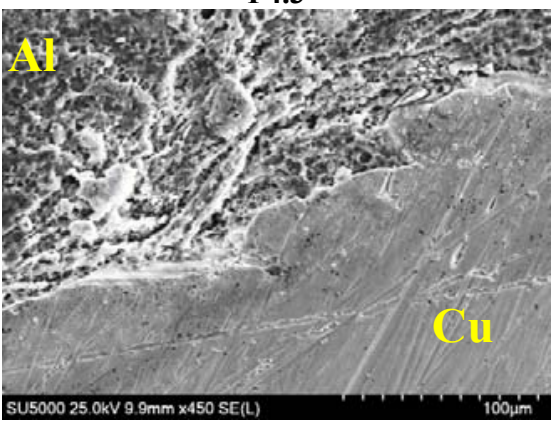

P4.5

Fig. 5. Morphology of joining area.

From the analysis of the joining area it can be seen that at the interface between the two materials there appear slip bands, micro-pores and voids. Some defects like voids can be associated with the insufficient material flow because at very low welding temperature. In fact, different melting temperatures and contraction coefficients of dissimilar sheets materials lead to this lap joint cavity defect.

$\mathrm{Cu}$ fragment were brought in the aluminum side. The distribution of $\mathrm{Cu}$ particles with irregular shapes and various sizes was inhomogeneous in the welding zone and a particles rich zone was formed.

Joint microstructure and chemical composition in areas (sites), marked in Figure 4 are shown in Figures 6-8.

In the analysis of the images it is observed that pieces of $\mathrm{Cu}$ are brought in the material made of Al, obtaining a mixture of the two materials. In all joining areas analyzed, in the chemical composition besides aluminum there is also copper.
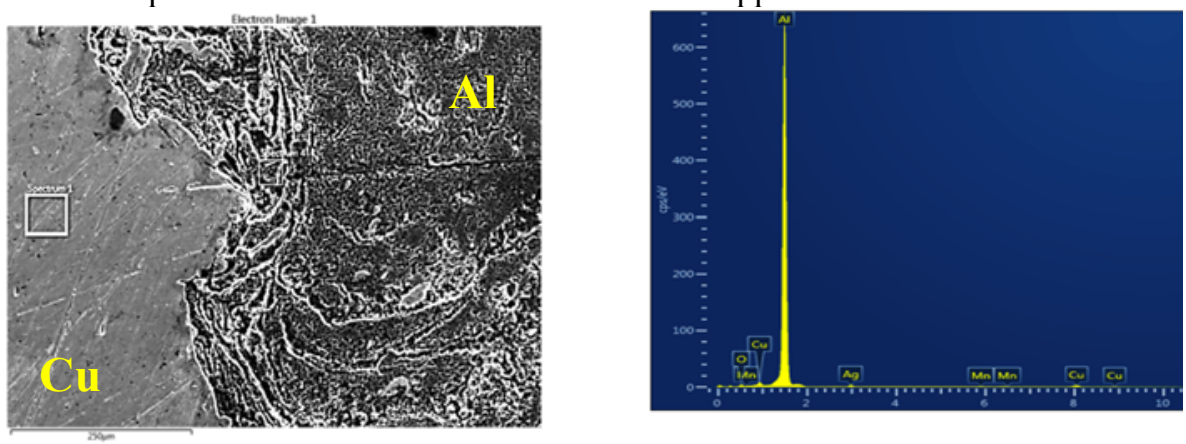

Fig. 6. Microstructure and chemical composition - Site 1, P4.1. 

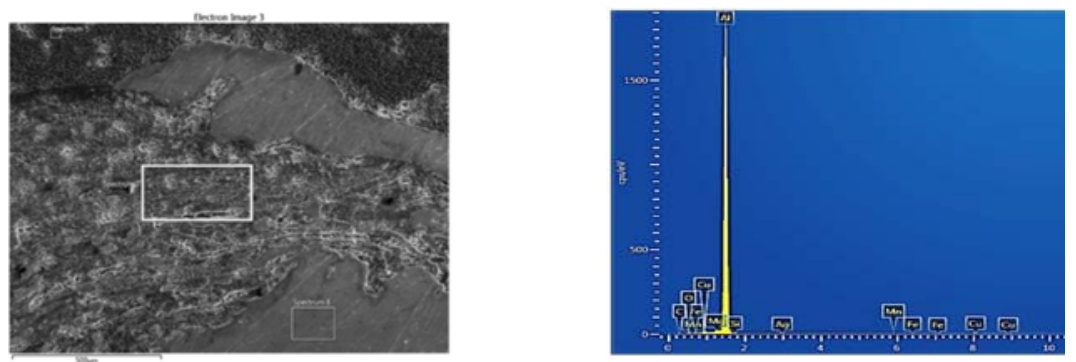

Fig. 7. Microstructure and chemical composition - Site 2, P4.2.
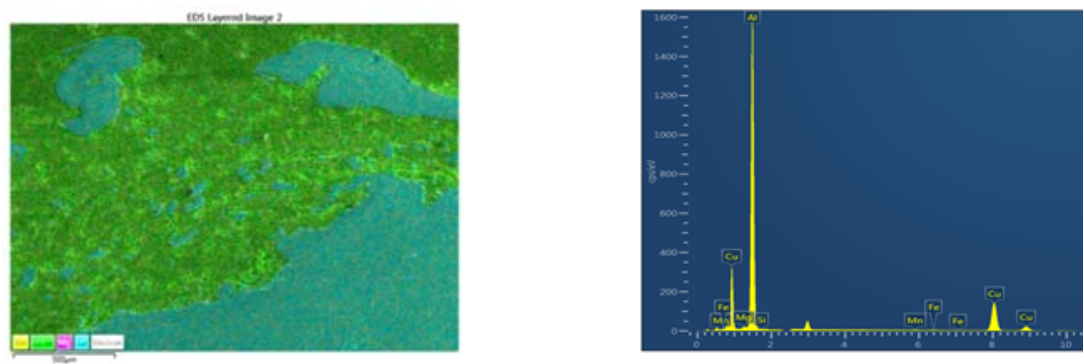

Fig. 8. Microstructure and chemical composition - Site 3, P4.4.

\subsection{Microhardness of the joint}

There was performed a line of microhardness, in the cross section of the joined parts, in the direction parallel to the outer surfaces of the joined parts at their mid-thickness. The load used was 300 grams, the step was of $1 \mathrm{~mm}$ and the determinations were made in 10 points. The values of microhardness thus obtained are shown in Figure 9.

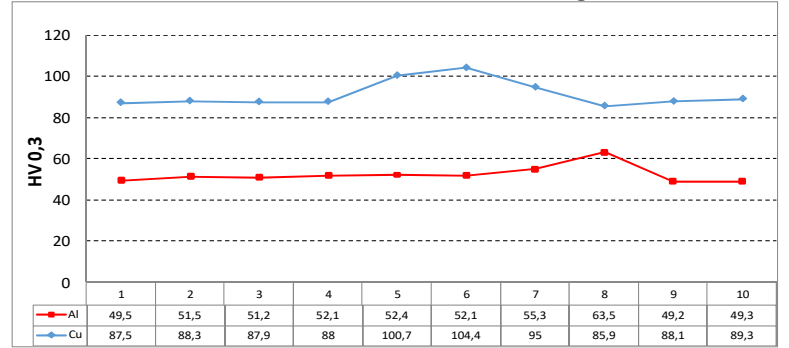

Fig. 9. Values and evolution of microhardness.

There are slight increases of microhardness in the joining area (measurement points 5, 6 and 7) for the $\mathrm{Cu}$ material. The values of microhardness in this area, in the $\mathrm{Cu}$ material are approximately $100 \mathrm{HV} 0.3$, being somewhat larger than the base material (about $87 \mathrm{HV} 0.3$ ). Hardness value increases significantly in welding zone relative to base metals because is fine grain microstructure caused by the dynamic recrystallization resulting from the combined role of heat and stirring force. Such increases were not identified for the Al material. 

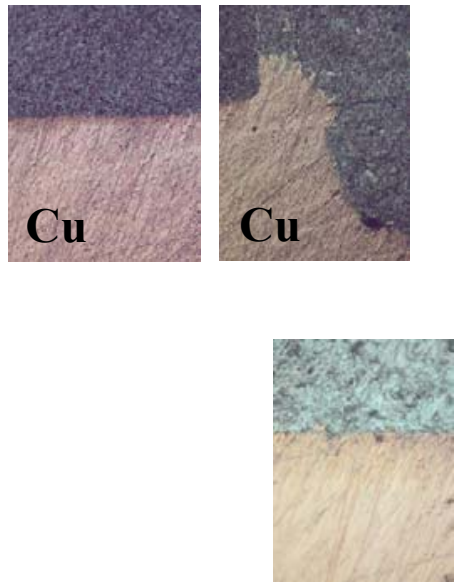
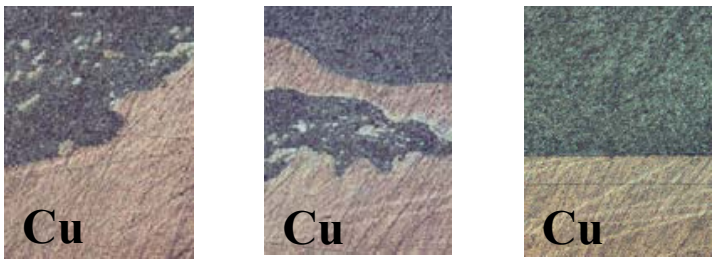

a)
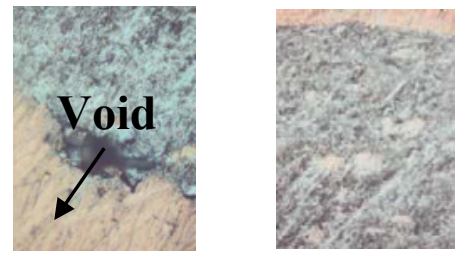

b)

Fig. 10. Micrographic aspects of the welded joint: a) increase $x 10, b)$ increase $x 50$.

\section{Conclusions}

A preliminary investigation has shown that FSW is an effective method of joining dissimilar materials. The FSW joint appeared to contain some evidence of micro-pores and voids at the interface of the aluminum and copper. Some defects like voids that show up at a region near the sheets interface especially in the $\mathrm{Cu}$ sheet because very low welding temperature the particle rich zone formed in the welding zone had a structure with variously sized particles dispersed in the $\mathrm{Al}$. As the pin is introduced into the area of $\mathrm{Al}$ in the core predominates $\mathrm{Al}$, and $\mathrm{Cu}$ is distributed in the form of pieces of irregular shapes. The portion of the core of the aluminum alloy is made of an area of the core, light-colored and located at the top of $\mathrm{Al}$ and an area under the previous one that contains many particles rich in $\mathrm{Cu}$ and which expands in the base material $\mathrm{Cu}$. The value of $\mathrm{Cu}$ micro-hardness in the core increases to $100 \mathrm{HV}$ and that of aluminum up to $63 \mathrm{HV}$.

This work was accomplished within the "Partnerships in priority areas - PN II" program, implemented with the support of Executive Agency for Higher Education, Research, Development and Innovation Funding (UEFISCDI) and Romanian Ministry of Education and Scientific Research, project no. PN IIPT-PCCA-2013-4-185. All authors are grateful to UEFISCDI for research funding.

\section{References}

1. Z. Shen, Y. Chena, M. Haghshenas, T. Nguyenb, J. Gallowayc, A.P. Gerlicha, Mater.Charact., 104 (2015)

2. X. Li, D. T.Zhang, C.Qiu, W.Zhang,Trans. Nonferrous Met. Soc. China, 22 (2012)

3. V.C. Sinha, S. Kundu, S. Chatterjee Perspect. Sci, 8 (2016)

4. P. Xue, D.R. Ni, D. Wang, B.L. Xiao, Z.Y. Ma. Mater Sci. Eng A 528 (2011)

5 Y.Demmouche, These pour obtenir le grade de docteur délivré par l’École Nationale Supérieure d'Arts et. Métiers Spécialité Mécanique - Matériaux (le 17 Décembre 2012)

6. J.E. Lee, D.H. Bae, W.S. Chung, K.H. Kim, J.H. Lee, Y.R. Cho, J. Mater. Process. Technol. 187-188 (2007)

7. Y.J. Guo, G.W. Liu, H.Y. Jin, Z.Q. Shi, G.J. Qiao, J. Mater. Sci. 46 (8) (2010).

8. L. Yang, B.X. Mi, L. Lin, H.J. Huang, X.P. Lin, X.G. Yuan,. Mater. Sci. For. 749 (2013)

9. J.Q. Zhang, Y.F. Shen, X. Yao, H.S. Xu, B. Li, Mat.\& Design. 64 (2014) 